\title{
CONTENIDO TEÓRICO DE LOS MÉTODOS DE REGULACIÓN MORAL DE LA CONDUCTA
}

\author{
The Orifical Content of the Methods of Moral Regulation of the Behavior \\ José Luis Aguilera Amaro, Lcdo. \\ Universidad de Oriente, Cuba \\ https://orcid.org/0000-0002-6022-1759 \\ jaguilera@uo.edu.cu \\ Maricelys Manzano García, Dra. C \\ Universidad de Oriente, Cuba \\ https://orcid.org/ 0000-0001-9786-4726 \\ maricelys@uo.edu.cu
}

Palabras claves: Moral, Regulación Moral, Mecanismos Reguladores, Métodos Reguladores.

Keywords: Moral, Moral Regulation, Mechanisms Regulators, Methods Regulators.
Recibido: 01 de octubre de 2020

Aceptado: 15 de enero de 2021

\section{RESUMEN}

El estudio de la temática moral es trascendental en el contexto actual, teniendo en cuenta los cambios y transformaciones vertiginosas que se experimentan, donde se aprecia la influencia de una crisis de la moralidad resultado, sobre todo, de la existencia de contradicciones entre múltiples sistemas morales, algunos antagónicos. Teniendo en consideración que la flexibilización extrema de la conducta, por un lado, y la coerción excesiva por otro, permean un escenario donde los sujetos no encuentran asidero certero para su comportamiento, es imprescindible el desarrollo de una concepción integradora sobre la regulación moral, destacando sus métodos reguladores. La propuesta tiene como objetivo exponer métodos de regulación moral de la conducta, como contribución a clarificar las pautas para este tipo de ejercicio.

\section{ABSTRACT}

The study of the thematic morals is momentous in the current context, keeping in mind the changes and vertiginous transformations that are experienced, where the influence of a crisis of the morality is appreciated, mainly, of the existence of contradictions among multiple moral systems, some antagonistic ones. Having in consideration that the extreme flexibilización of the behavior, on one hand, and the excessive coercion for other, permean a scenario where the fellows don't find good handle for their behavior, it is indispensable the development of an integrative conception on the moral regulation, highlighting their methods regulators. The proposal has as objective to expose methods of moral regulation of the behavior, as contribution to clarify the rules for this exercise type. 


\section{INTRODUCCIÓN}

La temática moral ha sido una de las más investigadas desde la Antigüedad. En la historia del pensamiento ético puede apreciarse una amplia diversidad y diferentes criterios al respecto, a pesar de ello, se evidencia consenso general entre sus estudiosos, el que ha permitido la concreción de su contenido como objeto de estudio específico de la Ética (Titarenko, 1983, T. 1, p. 157 y 160).

Las consideraciones al respecto han variado en correspondencia con las condiciones sociohistóricas, culturales y el modo de producir los hombres en cada época, desde la sociedad más "primitiva" hasta la más "civilizada" o contemporánea.

En el presente artículo se proponen, resultado de estudios realizados, métodos de regulación moral de la conducta, como contribución a clarificar las pautas para este tipo de ejercicio.

\section{DESARROLLO}

\section{Acercamiento a concepciones morales}

Las concepciones morales se han planteado de gran valor para el desarrollo humano puesto que este no se puede concebir al margen de un perfeccionamiento del comportamiento en sociedad, donde influyen postulados ideológicos preestablecidos (intereses de clase, grupos, sectores, colectivos), como indicativo de lo deseado o esperado (exigencias). En ese esquema la conciencia y actividad morales se han representado como ejes fundamentales que tributan a la materialización de ese objetivo.

La moral, se compone por un conjunto de factores subjetivo-objetivos como parte de su contenido que permiten no sólo comprender, sino también incidir de forma directa sobre la realidad social a través de la actividad práctica. Una de sus funciones esenciales es la regulación de la conducta. Se ha reconocido teniendo en cuenta su contribución al necesario orden y control social. Como sistema regulador complejo, se apoya en un conjunto de mecanismos y métodos morales que tributan a la prevalencia del bien o deber ser moral en relación con sus contrapartidas. Es inherente al individuo teniendo en cuenta su capacidad racional y necesidad de supervivencia, aspectos desarrollados de manera exponencial viviendo en colectividad.

El concepto de moral es uno de los más desarrollados en la historia del pensamiento ético universal, por lo que no es posible hacer referencia a todos los criterios al respecto. Debido a ello, se tienen en cuenta algunos, los más convenientes para su definición según el propósito fundamental de los realizadores de esta investigación científica (Titarenko, 1983, T. 1, p. 169; López, 1989, p. 105-112; López, 2004, T. 2, p. 58-59; Ulloa y Chacón, 1988, p. 44; Savater, 1993, p. 59). Los autores referidos se han centrado en el factor subjetivo o en las acciones humanas individuales como fenómeno concreto, conllevando a que, en la particularización de sus estudios, desestimen aspectos que tributarían a una comprensión más amplia e integradora sobre la moral.

Por ese motivo, teniendo en cuenta un punto de partida distinto sobre la complementariedad entre la dimensión subjetiva y objetiva de la realidad; se entiende por moral un modo de ser particular del individuo, quien posee un grupo de representaciones mentales reflejo de la naturaleza de sus relaciones, actividad y realidad, sociales, a partir de la contraposición entre lo que se ha establecido como bueno y malo en ese marco, sustentado en la significación positiva o negativa de sucesos, fenómenos, procesos, cosas y acciones sobre las personas. Por este motivo, es posible plantear que la lucha de contrarios es una manifestación natural en las relaciones morales. Se encarga de regular la conducta a través de unos mecanismos subjetivo-objetivos inherentes a ella de los que forman parte las normas, los principios, los juicios de valor y valores morales.

La moral se ha empleado entre otras formas, como instrumento de control y ordenamiento social. En este sentido, ella representa un sistema complejo de regulación de la conducta en el que se encuentran juicios de valor, mandatos, prescripciones o normas, principios y valores morales, que cuando se contraponen, incitando actos contradictorios, surgen conflictos morales. En este caso, el individuo se hace responsable de la consecuencia de su elección moral por escoger (de forma consciente y voluntaria) realizar una determinada acción, asumiendo su repercusión y trascendencia para los que le rodean (Titarenko, 1983, T.1, p.166-171). Por esta razón, en la actividad moral elabora una jerarquización flexible de prioridades con el propósito de concretar sus intereses, tratando de evitar lo más que puede, inconvenientes malestares, aunque en ocasiones sin éxito.

La regulación moral es una de las funciones principales de la moral. Las relaciones morales son un tipo de relaciones de poder, donde unos regulan y otros son regulados, unos mandan y otros obedecen. En la historia de la humanidad 
no ha podido ser de otra manera. En esa lógica de relacionamiento unos son los sometedores (dominadores) y otros los sometidos (dominados). Cuando no hay coincidencia entre los polos en pugna, por oposición y fractura de intereses, aspiraciones, necesidades, etcétera, entonces se genera el conflicto, de baja, mediana o alta intensidad, desencadenando un estado de cosas a partir de su expresión concreta en el contexto histórico dado, entre ellas la lucha revolucionaria y el progreso moral (Sánchez, 2006, p. 10-25; 33-41; 159-162).

\section{La regulación moral de la conducta}

Múltiples investigadores se han referido al tema de la regulación moral de la conducta. Sus trabajos consultados apuntan a dos direcciones distintas, aunque no divergen demasiado según su esencia, la relación contradictoria entre lo establecido como bueno y malo. Un grupo de resultados, los más numerosos, se circunscriben a la orientación autorreguladora, mientras que otros a la regulación externa del comportamiento. El estudio sobre estas vertientes ha conducido a que algunos de estos especialistas consideren la existencia de un sistema de regulación moral, del que forman parte los mecanismos reguladores, entre los que se encuentran sus métodos.

La regulación moral de la conducta se efectúa desde dos direcciones distintas, desde dentro (subjetividad) hacia afuera (realidad objetiva) y desde fuera hacia dentro. La primera perspectiva implica la autorregulación del comportamiento a través de la determinante incidencia de mecanismos psicológicos, la autovaloración como parte de los procesos racionales-emotivos de la conciencia. Por otra parte, la reguladora se asocia más a la influencia del medio social y el colectivo sobre la conducta individual, pues condiciona desde el nacimiento no sólo el conocimiento, las costumbres y los hábitos, sino incluso, los posibles cambios o transformaciones que se llevarán a cabo en el propio sistema moral o moralidad.

A partir de considerar algunos resultados científicos (Betancur, 2016, p. 109-121; Poblete, 2015, p. 9; entre otros) se puede plantear que la regulación moral además de ser un proceso social contradictorio, dinámico, formal-informal, micro-macro, subjetivo-objetivo, clasista, histórico-concreto, individual-colectivo, procedimental, progresivo, flexible, amplio, heterogéneo, etc., es sobre todo complejo, teniendo en cuenta los rasgos antes señalados y un grupo de factores (variables) que intervienen en el mismo tales como:

1. Las situaciones o circunstancias de elección moral;

2. La motivación del acto;

3. Las características del agente regulador (sujeto o colectivo defensor del código moral -normas, valores y principios morales-, es quien incentiva a que se cumplan u obedezcan las exigencias en el momento, conocido también como "agente censor". El mismo puede tener una actitud pasiva o activa que influye en el proceso de regulación moral);

4. El desarrollo de la conciencia moral;

5. Las condiciones materiales de vida del contexto histórico-concreto;

6. La percepción en torno a los resultados obtenidos por las acciones realizadas;

7. La efectividad o no de los medios, métodos, mecanismos, instrumentos empleados durante la actividad;

8. Los intereses;

9. El cúmulo de conocimiento y dominio de la información;

10. La experiencia atesorada;

11. La operatividad o pertinencia de normas, reglas o lineamientos;

12. La viabilidad de las alternativas;

13. Las representaciones, sensaciones, sentimientos (confusión, culpa, arrogancia, tristeza, entre otros), estados de ánimo, utopías, fantasías, aspiraciones, percepciones, impresiones, inquietudes, necesidades, que intervienen e interactúan en una o múltiples acciones;

14. El impacto de las enfermedades, el nacimiento y la muerte;

15. La relación éxitos-fracasos;

16. El proceso de crecimiento, desarrollo y maduración de la personalidad;

17. La cualidad del sistema de relaciones sociales.

La función moral reguladora se efectúa sobre todo a través de: limitar las aspiraciones negativas de las personas; la autorregulación de la persona y el entorno social; gestión de las relaciones públicas; realización de la moralidad humanista. (Propiedades y funciones de la moral, 2016) Teniendo en cuenta el presente planteamiento, se puede aludir a la existencia de un conjunto de pautas en el proceso de regular el comportamiento en sociedad, sin las que sería imposible lograrlo. Sin embargo, no sólo se trata de limitar aspiraciones negativas. 
En la actividad práctica, en las relaciones sociales se establecen patrones o códigos morales de comportamiento que se sustentan en diversas posibilidades de elección moral, oscilando entre limitaciones y permisibilidades (lo validado, promovido), como garantía de realización humana.

Atendiendo a la significación de la regulación moral y las motivaciones de los autores de este artículo científico, se establece como propósito central analizar el contenido teórico de los métodos de regulación moral de la conducta a partir del criterio de varios investigadores.

Una valoración de los mismos se expresa en las siguientes valoraciones: El uso del término mecanismo asociado a cuestiones sociales resulta ser controversial, teniendo en cuenta que es propio de disciplinas científicas o ciencias del área técnica. Desde el punto de vista mecanicista es definido por ejemplo como: "los elementos de una máquina destinados a transmitir y transformar las fuerzas y movimientos desde un elemento motriz, llamado motor a un elemento receptor; permitiendo al ser humano realizar trabajos con mayor comodidad y/o, menor esfuerzo (o en menor tiempo)." (Landin, (s.f), p. 1) En otra definición se plantea que es: “... una parte mecánica de una máquina, cuya función es transmitir movimiento y fuerza de una fuente de potencia a una salida. Es el corazón de la máquina." (Myszka, 2012, p. 2) Como estos, se pueden encontrar variados conceptos con ese mismo sentido y significado. No obstante, el término tiene otras implicaciones, ya que también es aplicado al campo social (Romero, 2002, T. 2, p.112; Titarenko, 1983, T. 1. p. 54).

Este punto de vista asociado a la moral como fenómeno social reconoce dos especificidades, la autorreguladora, circunscrita al terreno individual, subjetivo e interno del ser humano, mientras que, la reguladora, por el contrario, al colectivo, lo concreto y externo. A los pensadores que consideran lo interior como lo determinante se les denomina internalistas/subjetivistas, mientras que externalistas/objetivistas, a los que por el contrario creen que el entono social es lo primario. Se pudiera establecer un listado interesante de autores, pero atenerse de reduccionismos resulta conveniente.

Se evidencia así el doble carácter, interno-externo (subjetivo-objetivo) de la moral como "sistema" y "mecanismo" de regulación del comportamiento en sociedad. En este sentido, representa un conjunto de mecanismos que intervienen en el proceso regulador a partir de impulsar el bien o deber ser en relación inversa a sus contrapartidas. Se manifiestan de dos formas o modos distintos, desde afuera hacia adentro y desde adentro hacia afuera, o sea, desde la realidad objetiva hacia la subjetividad y viceversa. Sin embargo, resaltar que la relación entre ambos no es direccional ni unilateral, sino bidireccional y bicondicionada.

Atendiendo a lo expuesto, se plantea que la moral como sistema de regulación del comportamiento en sociedad posee dos mecanismos tales como: el mecanismo subjetivo (psicológico, autovalorativo-autoreflexivo, interno, espiritual, psíquico) de regulación moral de la conducta y el mecanismo objetivo (social, realista-objetual, externo, material, concreto) de regulación moral de la conducta. Ambos funcionan de modo integrado. Su interrelación es dialéctica y compleja, conduciendo sus contradicciones inherentes al progreso moral. Estos también se determinan mutuamente y según las autoras de Educación moral tienen a la base material como sustento de su dinámica (Ulloa y Chacón, 1988, p. 74-76). Son varios, algunos investigadores se han referido a ello, sin embargo, sólo se particulariza en los métodos reguladores por ser objeto de este estudio.

Concerniente a los métodos de regulación moral de la conducta, es importante señalar que forman parte de estos mecanismos. Al respecto, Titarenko (1983, T.1, p.180-181) realiza una diferenciación interesante entre índice objetivo y método, ya que no emplea el mismo término para hacer alusión a fenómenos similares, con un origen y finalidad común, no obstante, no aclara los criterios de los que parte para establecer esta distinción.

Él apunta una idea significativa al referirse a los sentidos opuestos que adquieren las sanciones en la cotidianidad, uno negativo y otro positivo. A pesar de ello, su reflejo mental es tendiente por lo general a representarlas como represión y condena, no como aprobación. De cualquier modo, reconoce la trascendencia de la coerción y persuasión para la regulación moral de la conducta en la sociedad socialista, cuestión que se trata poco en algunos espacios de reflexión colectiva.

Teniendo en cuenta que el autor mencionado no desarrolla con suficiente argumentación esta teoría, se establece un criterio de clasificación. En opinión de los realizadores de esta investigación el primer término guarda más relación con el cómo (estrategias), mientras que el segundo, con él a través de qué (instrumentos o herramientas), lo que se manifiesta de una manera espontánea, sin premeditación.

Los métodos morales de regulación son subjetivos-objetivos, forman parte de los mecanismos y del sistema regulador de la moral. Representan un conjunto de instrumentos, procedimientos, resortes o técnicas de regulación moral que tributan al ordenamiento social a través de intentar hacer prevalecer lo bueno en relación a su contrario. 


\section{Métodos de regulación moral de la conducta}

Las consideraciones anteriores permitieron delimitar los siguientes métodos:

Objetivos: Orientación; valoración, evaluación o reflexión; crítica, cuestionamientos, censura, señalamientos; procedimientos, técnicas y protocolos de intervención; sanciones o penalidades menores; recompensa; diálogo; exigencia; imposición; reprimendas, regaños o llamados de atención; vigilancia, guarda o cuidado; el control, fiscalización o examen; dirección, conducción o administración; persuasión o convencimiento; la clasificación y periodización; denuncias (Díaz-González, Zaira y Cantorán, 2008, p. 65-75; Titarenko, 1983, T. 1, p. 180-181).

Subjetivos (Funcionan sobre todo a nivel de la conciencia, son procesos que se efectúan en vigilia. Se desarrollan en forma gradual de conjunto con la personalidad. Poseen un carácter individual marcado, aunque el colectivo también puede hacer uso de ellos)

Autocrítica. Proceso autoreflexivo a través del que se juzga y critica un individuo a sí mismo.

Autocoacción, autoprohibición, autoreprensión; cohibirse de realizar determinados actos.

Autocontrol. Capacidad de realizar acciones en correspondencia con las convicciones o principios morales personales a pesar de la influencia de circunstancias concretas externas.

Autopersuación. El individuo se convence a sí mismo y se anima a realizar una determinada actividad.

Autoexigencia. Acción de autoimponerse deberes y los límites, cuotas, metas o parámetros personales se superan.

Autovaloración, autoexamen, autoevaluación, autoanálisis. Procesos autoreflexivos sobre la propia personalidad que ameritan de un juicio moral valorativo. La cultura (saberes, sensaciones, sentimientos) y los grados de madurez influyen en este y su resultado.

Intereses. Anhelos, deseos o aspiraciones concretas, fundamentales, que motivan o movilizan a la realización de una determinada actividad.

Aspiraciones. Deseos que se pretenden alcanzar, no siempre se encuentran en correspondencia con las condiciones materiales y espirituales del sujeto, de ahí que puedan ser utopías o intereses.

Autorreconocimiento. Proceso consciente de conocerse a sí mismo, identificarse y diferenciarse de todo cuanta rodea a ese ser humano en particular, sobre todo de sus semejantes.

Autoaceptación. Proceso consciente de estar conforme consigo mismo, satisfecho de lo que se es como ser humano, de los pensamientos, sentimientos y conductas que se realizaron, realizan o se pueden realizar.

Audesaprobación. Proceso consciente de no estar conforme consigo mismo, insatisfecho de lo que se es como ser humano, de los pensamientos, sentimientos y conductas que se realizaron, realizan o se pudieran realizar.

Objetivos. (Porque existen fuera de la subjetividad humana desde el punto de vista concreto, se quiera o no, a pesar de la voluntad. Desde que el individuo nace en sociedad se encuentra un conjunto de mecanismos objetivos reguladores de su comportamiento)

Orientación. Asociada al fenómeno moral, es el proceso mediante el cual se establecen pautas de comportamiento, evaluación, estudio, trabajo, entre otros, para que los sujetos se guíen al momento de la realización de sus acciones.

Valoración, evaluación o reflexión. Representa una expresión crítica amparada en juicios de valor (relación positivonegativo) que el ser humano realiza de la realidad, su condición humana y su estatus social, que lo conduce a la transformación o conservación de sus condiciones de vida, tributando también a la regulación moral de la conducta.

Crítica, cuestionamientos, censura, señalamientos. Constituye el acto a través del que se exponen sobre todo los defectos o insuficiencias asociados al comportamiento humano y al mismo tiempo las propuestas de su superación.

Recompensa. Recurso que se emplea con el propósito de incentivar y estimular comportamientos aceptados.

Exigencia. Desde el punto de vista moral, es una acción que implica la reclamación (verbal o gestual) por el incumplimiento de un deber o cercenamiento de derechos.

Prohibiciones. Acción de prohibir la escenificación de comportamientos inaceptables, es además establecer requerimientos que no se pueden violar, sólo bajo circunstancias bien justificadas. 
Imposición moral. Acción de colocar a un individuo o colectivo en la obligación de cumplir una determinada orden, acción, tarea o actividad, guste o no, sucede en ocasiones bajo amenazas (exceptuando las de muerte) y chantajes.

Regaños, llamados de atención, condena, reprimendas. Es la acción para muchos, molesta, para otros, necesaria, de imponer a las personas que se considera cometen un error o tienen un mal comportamiento de la inconformidad referente a ese tipo de práctica.

Loas y alabanzas. Constituye el acto a través del que se manifiesta aceptación, conformidad, alegría, complicidad en torno a capacidades, actitudes, comportamientos y expresiones verbales.

Vigilancia, guardia o cuidado. Son conceptos a los que se le otorga una significación diferente. La vigilancia ha recibido un tratamiento teórico importante vinculado a la sociedad desde una perspectiva de análisis sociopolítica, pues se ha relacionado con las dinámicas públicas de los regímenes democráticos de corte burgués. Los otros, desde el punto de vista moral, se asumen como procesos sociales similares.

Por lo tanto, se entiende como la acción de estar pendientes, apercibidos, preparados, dominantes de la información, conscientes a plenitud, de cuanto acontece alrededor, sobre todo, de las conductas morales indebidas que afectan el dinamismo social cotidiano, con el propósito de proteger a las personas de las injusticias y malas prácticas.

Control, fiscalización o examen. Son términos que adquieren significados distintos de manera usual. Proceso, que circunscrito al ámbito de la regulación moral estriba en utilizar todos los recursos disponibles con que se cuente para corroborar, inspeccionar, comprobar, chequear de forma intencionada, por lo general planificada, que un comportamiento o conducta moral se apegue a lo aceptado como correcto en la sociedad.

Dirección, conducción o administración. Proceso, a través del que se organiza, conduce y coordina la actividad humana colectiva, así como los acontecimientos o hechos sociales, ejerciendo influencia de forma intencionada sobre el individuo con el propósito de concretar determinados objetivos específicos comunes.

Diálogo, persuasión o convencimiento. Es una manera de influir, condicionar el comportamiento de las personas a través de la palabra (conversación) con el empleo de los argumentos racionales-emotivos necesarios.

Clasificación y periodización. Son dos procesos distintos, sin embargo, el segundo implica el primero. Clasificar es el acto a través del que se distinguen, agrupan, organizan, separan, fenómenos, cosas o personas por medio de establecer semejanzas y diferencias sobre la base de un grupo de criterios.

Desde la perspectiva de la regulación moral se esquematizan situaciones de elección moral, individuos, conductas, etcétera, condicionando en reiteradas ocasiones comportamientos específicos o determinadas tendencias, algunas contrarias a las exigencias sociales, de ser así, entonces los sujetos quedan expuestos al escarnio y juicio moral.

Denuncias. Constituye uno de los métodos reguladores más importantes, pero al mismo tiempo uno de los más peligrosos, porque puede generar represalias de parte de los sujetos afectados. Se relaciona con la honestidad y la valentía como valores morales. La denuncia moral es la exposición en público o a la autoridad competente sobre un comportamiento reprochable, indigno y hasta criminal.

Ninguno de estos métodos de regulación moral por sí solo puede garantizar un buen comportamiento moral, es fundamental su articulación. Porque es necesario un alto grado de desarrollo de la conciencia moral, la aceptación consciente, voluntaria o el consentimiento para que una norma o mandato bajo cualquiera de estas formas sea efectivo, algunos investigadores sobredimensionan el rol regulador de la subjetividad, cayendo en posiciones parcializadas 0 reduccionistas.

La regulación moral de la conducta se efectúa a partir del pleno ejercicio consciente de la libertad individual (para hacer el bien) y la influencia externa de agentes reguladores que aplican estos mecanismos reguladores, sobre todo este tipo de métodos objetivos de regulación moral.

\section{CONCLUSIÓN}

La regulación de la conducta es una de las funciones principales de la moral. La regulación moral de la conducta se efectúa desde dos direcciones distintas, de adentro hacia afuera y viceversa. La primera refiere el proceso de autorregulación del comportamiento, en tanto la segunda, la acción reguladora del colectivo. 
La moral representa un sistema de ideas, acciones y relaciones con un carácter social. Encarna un conjunto de factores de carácter interno-externo asociados al modo de ser del sujeto que de forma interrelacionada hacen posible su funcionamiento como ente moral. Los mecanismos de regulación moral subjetivo-objetivo incluyen los métodos reguladores del comportamiento.

Los métodos de regulación moral de la conducta son subjetivo-objetivo y contribuyen al ordenamiento, funcionamiento, organización y progreso social a partir de su uso correcto.

\section{BIBLIOGRAFÍA}

1. Betancour J., G. E. (2016). La ética y la moral: paradojas del ser humano. CES Psicología, Vol. 9, n. 1, enerojunio. Universidad CES, Medellín, Colombia.

2. Díaz-González A., E., Zaira V., C. y Cantorán T., E. (2008). Identificación de los modos de regulación moral en padres desde una perspectiva interconductual. En Enseñanza e Investigación en Psicología, vol. 13, n. 1, enero-junio.

3. Kochanska, G. y N. Aksan (2006). Temperament, relationships, and young children's receptive cooperation with their parents. Developmental Psychology, 41 (4).

4. Landin, P. (s.f): Máquinas y mecanismos. http://www.pelandintecno.blogspot.com/

5. López A, J. L. (1989). Ética de la felicidad y otros lenguajes. Editorial Tecnos, S.A., Madrid.

6. López B, L. R. (2004). El Saber Ético de Ayer a Hoy. Editorial Félix Varela, La Habana, T. 2.

7. Mvszka, D. H. (2012). Máquinas y mecanismos. Cuarta edición, Pearson Educación, México.

8. Petrovski, A. (1990). Psicología General. Editorial Pueblo y Educación. La Habana.

9. Poblete, L. (2015). Modos de regulación del trabajo doméstico. Cuadernos del ides. N.30, Serie proyectos de investigación, Instituto de Desarrollo Económico y Social, Buenos Aires. Octubre.

10. Romero P., C. L. (2002). La actividad moral en tiempos de globalización. En Ética y sociedad. Editorial Félix Varela, La Habana, T.1.

11. Sánchez V, A. (2006). Entre la realidad y la utopía. Editorial Ciencias Sociales, La Habana.

12. Savater, F. (1993). Ética para Amador. Editorial Ariel, Barcelona, España.

13. Titarenko, A. I. (1983). Ética Marxista. Ediciones Enspes, La Habana. T. 1.

14. Ulloa J, H. y Chacón A, N. (1988). Educación Moral. Ciencias Sociales, La Habana.Batista, I.; Lema, A. y Delgado, E. La Motivación y Orientación Educativa. http://ojs.formacion.edu.ec/index.php/rif/article/view/12 DOI: https://doi.org/10.34070/rif.v1i1 